\title{
INFLUÊNCIA DA APLICAÇÃO DE REVESTIMENTO COMESTÍVEL EM QUEIJO MINAS ARTESANAL DURANTE O PERÍODO DE MATURAÇÃO
}

\author{
G. S. LEÃO ${ }^{1}$, L. S. SILVA ${ }^{2}$, A. P. C. MADEIRA ${ }^{3}$, V. A. V. QUEIROZ ${ }^{4}$, C. V. PIRES ${ }^{5}$, M. R. SOUZA ${ }^{6}$, A. M. SILVA \\ Universidade Federal de São João del-Rei, Campus Sete Lagoas ${ }^{1,2,3,5,7}$ \\ Empresa Brasileira de Pesquisa Agropecuária, Embrapa Milho e Sorgo ${ }^{4}$ \\ Universidade Federal de Minas Gerais, Escola de Veterinária ${ }^{6}$ \\ amsilva@ufsj.edu.br ${ }^{7}$
}

Submetido 22/06/2020 - Aceito 22/12/2020

DOI: $10.15628 /$ holos. 2020.10547

\section{RESUMO}

O queijo Minas Artesanal (QMA) é produzido a partir de leite bovino integral cru, coalho e soro-fermento, logo após a ordenha. Revestimentos comestíveis são películas feitas à base de amido, aplicados com objetivo de prolongar a vida de prateleira ou incorporar algum nutriente. Este trabalho avaliou o efeito da aplicação de um revestimento comestível em QMA produzido na mesorregião do Campo das Vertentes (Minas Gerais/Brasil) e verificou a possibilidade de diminuição do tempo de maturação deste produto. As amostras foram submetidas a análises microbiológicas e físicoquímicas com 4, 14 e 22 dias de maturação. Com exceção dos resultados de coliformes a $30^{\circ} \mathrm{C}$, todos os demais dados tornam o QMA apto para o consumo com 14 dias de maturação. As bactérias ácido-láticas foram os micro-organismos predominantes nas amostras. Os resultados médios das análises físico-químicas para as amostras controle e tratamento, respectivamente, foram: $\mathrm{pH}=5,2$ e 5,1; acidez titulável = 1,3 e 1,2 g de ácido lático/100 g de amostra; gordura 30,9 \% e 31,4 \%; extrato seco $=66,0 \%$ e $66,2 \%$; umidade $=34,0 \%$ e 33,8 $\%$; gordura no extrato seco $=46,8 \%$ e $47,1 \%$ e proteínas $=22,6 \%$ e $23,0 \%$. Não houve diferença estatística $(p>0,05)$ entre os parâmetros microbiológicos e físicoquímicos pesquisados. Conclui-se que o revestimento não alterou significativamente os parâmetros avaliados, mas este estudo indica a possibilidade de diminuição do tempo de maturação para comercialização deste produto.

PALAVRAS-CHAVE: controle de qualidade, embalagem ativa, Campo das Vertentes, compostos antimicrobianos.

\section{INFLUENCE OF THE APPLICATION OF EDIBLE COATING IN MINAS ARTISANAL CHEESE DURING THE MATURATION PERIODO}

\begin{abstract}
Minas artisanal cheese is produced using bovine raw whole milk, rennet and endogenous starter cultures, soon after the end of the milking. Edible coatings are films made from starch, applied with the objective ' of extending the shelf life or incorporating some nutrient. This work evaluated the effect of applying an edible coating in Minas artisanal cheese produced in the region of Campo das Vertentes, Brazil, and verified the possibility of reducing the maturation time of this product. These samples were submitted to microbiological analyses and physicochemical characterization with 4, 14 and 22 days of aging. With the exception of coliform at $30{ }^{\circ} \mathrm{C}$ counts, all other data made the cheese fit for consumption at 14 days of
\end{abstract}

aging. Lactic acid bacteria were the predominant microorganisms in the samples. The mean results of the control and treatment samples, respectively, for physicochemical analyses were: $\mathrm{pH}=5.2$ and 5.1; titratable acidity $=1.3$ and $1.2 \mathrm{~g}$ of lactic acid $/ 100 \mathrm{~g}$ sample; fat 30.9 and $31.4 \%$; total solids $=66.0$ and 66.2 $\%$; moisture $=34.0$ and $33.8 \%$; fat in total solids $=46.8$ and $47.1 \%$ and proteins $=22.6$ and $23.0 \%$. There was no statistical difference between the studied microbiological and physicochemical parameters. It is concluded that the coating did not significantly change the evaluated parameters, but this study indicates the possibility of reducing the aging time for commercialization of this product.

KEYWORDS: quality control, active packing, Campo das Vertentes, antimicrobial composites. 


\section{INTRODUÇÃO}

O queijo Minas artesanal (QMA) é produzido a partir de leite cru, integral, recém ordenhado de vaca, obtido de um rebanho sadio e que atenda aos padrões de qualidade exigidos pela legislação estadual vigente (Minas Gerais, 2012), sendo seu modo de elaboração parte da cultura de um povo, e constituindo um patrimônio a ser preservado. Estes queijos são produzidos em queijarias credenciadas no estado de Minas Gerais com base em receitas tradicionais ao longo de diferentes gerações, e que possuem como característica marcante a utilização do pingo, fermento endógeno coletado da dessora da produção do dia anterior (Santos, 2016). O Instituto Mineiro de Agropecuária (IMA) reconhece sete regiões tradicionais produtoras de QMA, que são: Serro, Cerrado, Araxá, Serra da Canastra, Campos das Vertentes, Triângulo Mineiro e Serra do Salitre (Dores \& Ferreira 2012; Minas Gerais, 2014a; Minas Gerais, 2014b).

De acordo com o Instituto Brasileiro de Geografia e Estatísticas (IBGE), Minas Gerais é dividida em 12 mesorregiões e 66 microrregiões (IBGE, 2010). A região de Campos das Vertentes é uma das doze mesorregiões e foi identificada oficialmente como produtora de QMA no ano de 2009, a partir do Programa de Queijo Minas Artesanal executado pela EMATER-MG (IMA, 2009). A mesorregião dispõe de um ambiente rico para produção do QMA, caracterizado por um solo fértil, grandes rebanhos leiteiros e inúmeros cursos d'água. Historicamente, a região do Campo das Vertentes rapidamente assumiu o papel de grande centro comercial, no qual o queijo se tornou o principal alimento de compra e venda (Saint-Hilaire, 1974; Lemos, 2009).

A maturação do queijo Minas artesanal ocorre, normalmente, em temperatura ambiente por período de tempo variável, para que haja o desenvolvimento de suas características específicas, como aparência, cor, sabor e textura, por exemplo, resultantes do desenvolvimento da microbiota desejável e consequentes alterações bioquímicas no queijo, devidas às ações de enzimas proteolíticas e lipolíticas, e favorece a fermentação lática que resulta na inibição de micro-organismos contaminantes nos queijos (Dores \& Ferreira, 2012; Silva et al., 2019). A Instrução Normativa No 57 do MAPA (Brasil, 2011) e, mais recentemente, a atualização do RIISPOA em 2017 (Brasil, 2017), estabeleceram que o período de maturação poderia ser modificado de acordo com a realização de estudos científicos regionais conclusivos que consigam comprovar a inocuidade do produto no período de maturação proposto. Os produtores também têm interesse em comercializar os queijos com menor tempo de maturação, que atualmente é de 14 dias para a microrregião de Araxá, 17 dias para a microrregião do Serro e 22 dias para a Serra da Canastra e demais microrregiões, na qual se inclui o Campo das Vertentes, segundo a Portaria No 1.736/2017 (Minas Gerais, 2017).

O queijo, devido às suas características, é um alimento propício à contaminação, desde sua produção até o processo de embalagem, lembrando ainda que este último não é obrigatório para o QMA. Nas últimas décadas, estudos de filmes à base de biopolímeros têm sido realizados, uma vez que esses materiais têm o potencial de diminuir o número de embalagens tradicionais e, portanto, reduzindo os impactos e a contaminação ambiental que é muito comum pelo elevado número de embalagens não biodegradáveis lançados anualmente na natureza (Zamudio-Flores et al., 2009). O uso desta barreira visa reduzir a perda de umidade, diminuir as taxas de respiração, 
atuar na manutenção da cor, dar um aspecto brilhante e mais atrativo ao produto, conservando as propriedades estruturais, elevando sua vida útil (Stülp et al., 2012; Fai et al., 2015).

O amido vem sendo muito empregado para a produção de revestimentos comestíveis devido à sua abundância e baixo custo. Ademais, os revestimentos comestíveis de amido possuem outras características atrativas, como serem transparentes, incolores e inodoros, facilitando a aplicabilidade em diferentes alimentos (Lopes et al., 2018). A fécula de mandioca, na conservação de alguns produtos vegetais, vem se mostrando bastante efetiva na manutenção das características sensoriais e, em concentração de 2,0 \%, foi capaz de minimizar a perda de massa, promover o aumento de vitamina C e elevar a vida útil de mamão 'Formosa' (Nunes et al., 2017). Visando uma maior usabilidade do revestimento comestível, ele pode ser incorporado com substâncias antimicrobianas, tais como ácido málico e óleos essenciais de canela, palmarosa e capim-limão, criando outra barreira no alimento e, consequentemente, mantendo-o mais seguro durante o armazenamento (Raybaudi-Massilia et al., 2008; Sapelli et al., 2020).

Em estudo realizado por Kil et al. (2009), o extrato de compostos fenólicos do sorgo mostrou-se eficiente no controle de diversos micro-organismos patógenos, destacando-se Staphylococcus aureus, Escherichia coli, entre outros, e também apresenta compostos antioxidantes, se mostrando uma boa opção para ser adicionado ao revestimento comestível. Os compostos fenólicos apresentam duas categorias, os flavonoides e os não flavonoides, e são eles os responsáveis pela ação antimicrobiana e antioxidante do grão, respectivamente (Awika \& Rooney, 2004). Nos alimentos, servem para evitar que eles sejam deteriorados e no corpo humano, as substâncias antioxidantes oriundas da dieta ajudam o mecanismo de defesa no controle dos danos causados nas células pelos radicais livres, auxiliando na prevenção de doenças crônicas, como o câncer (Tiveron et al., 2012; Sousa et al., 2020). O genótipo SC319 é uma variedade de sorgo que apresenta elevados teores de compostos fenólicos, conferindo ao seu pericarpo a coloração vermelha (Oliveira et al., 2017).

Este trabalho objetivou avaliar o efeito da aplicação de um revestimento comestível feito a partir da fécula de mandioca e adicionado de compostos fenólicos presentes no grão de sorgo, em queijos Minas artesanal, produzidos e maturados à temperatura ambiente na mesorregião do Campo das Vertentes, e verificar a possibilidade de diminuição do tempo de maturação destes produtos. Como objetivos secundários, buscou-se estabelecer a produção/composição do revestimento comestível, definir o melhor dia correspondente a maturação dos queijos para aplicação do revestimento comestível elaborado e avaliar as características microbiológicas e físico-químicas do queijo Minas artesanal, durante o período de maturação.

\section{METODOLOGIA}

\subsection{Produção do revestimento comestível e definição do dia de aplicação no QMA}

O revestimento comestível foi produzido a partir da fécula de mandioca, no Laboratório de Embalagens da UFSJ/CSL, seguindo o protocolo apresentado por Queiroz et al. (2010). A fórmula do extrato de compostos fenólicos do sorgo foi doada pela Embrapa Milho e Sorgo, localizada na cidade de Sete Lagoas/MG. Para a produção desse extrato utilizou-se água 
acidificada com $3 \%(\mathrm{~m} / \mathrm{v})$ de ácido cítrico e misturou-se com $4 \%(\mathrm{~m} / \mathrm{v})$ de uma farinha obtida do pericarpo do sorgo SC319, espécie que apresentou melhores resultados no trabalho de Barbosa e Queiroz (2018). Essa mistura ficou sob agitação em banho maria aquecido à $90{ }^{\circ} \mathrm{C}$ por $1 \mathrm{~h}$, foi centrifugada a $24860 \times \mathrm{g}$ (Novatecnica NT835/Piracicaba) e filtrada em filtro de papel faixa rápida, com o intuito de se retirar materiais flutuantes.

A partir deste extrato da farinha de pericarpo do sorgo, procedeu-se uma mistura com a fécula de mandioca (Amafil/Cianorte), adquirida no comércio local, até completa gelatinização do amido. Na sequência, a pasta formada foi resfriada, pelo contato da vidraria utilizada no preparo com água corrente, para formação do gel com consistência firme e adicionou-se glicerina (plastificante, Synth/Diadema) para formar o revestimento comestível. O revestimento foi acondicionado em vidro esterilizado e mantido sob refrigeração em caixas de isopor contendo gelo reciclável, aproximadamente a $4{ }^{\circ} \mathrm{C}$, até o momento de sua utilização.

Testes pilotos com QMA adquiridos em Sete Lagoas e com QMA obtidos na mesorregião de Campo das Vertentes foram realizados, em duplicata, com a finalidade de determinar qual o melhor dia de maturação dos queijos para aplicação do revestimento comestível.

\subsection{Amostragem e aquisição do QMA}

Os queijos Minas artesanais foram coletados em três fazendas, localizadas nas cidades de Tiradentes, São João del-Rei e Coronel Xavier Chaves, mesorregião de Campo das Vertentes/MG, em novembro de 2019 (período chuvoso). Foram obtidas seis amostras de cada propriedade, com quatro dias de maturação. Destas, três receberam o revestimento comestível na própria queijaria (tratamento), e as outras três amostras não receberam o revestimento, sendo consideradas controles. Os queijos eram do mesmo lote de produção.

O transporte para a Universidade Federal de São João del-Rei, Campus Sete Lagoas (UFSJ/CSL), ocorreu em caixas de isopor contendo gelo reciclável. As primeiras amostras foram levadas no mesmo dia de aplicação do revestimento comestível para realização das análises nos laboratórios de Microbiologia de Alimentos e de Análise de Alimentos da UFSJ/CSL. As amostras subsequentes, com 14 e 22 dias de maturação, continuaram nas fazendas para maturar (temperatura média na época de $17^{\circ} \mathrm{C}$ a $26^{\circ} \mathrm{C}$ ), assim como ocorre no processamento normal dos queijos comercializados pelos produtores, até que foram enviadas para a UFSJ/CSL nos dias pré-determinados.

\subsection{Análises microbiológicas}

As amostras de queijo foram submetidas às análises microbiológicas quanto aos microorganismos indesejáveis: número mais provável de coliformes a $30{ }^{\circ} \mathrm{C}$ e $45{ }^{\circ} \mathrm{C}$, contagem de Estafilococos coagulase positivo e pesquisa de Salmonella spp., que constam na Portaria $\mathrm{N}^{\circ} 146$, de 7 de março de 1996 (Brasil, 1996), conforme disposição no anexo II - Regulamento Técnico Geral para a fixação dos requisitos microbiológicos de queijos, requisito 3.2, para queijos de média umidade ( $36 \%<$ umidade $<46 \%$ ). Ademais, foram realizadas contagem total de bolores e leveduras, além de contagem total de bactérias ácido-láticas. 
As análises seguiram os procedimentos descritos em Silva et al. (2010) que estão de acordo com as metodologias oficiais e foram realizadas no Laboratório de Microbiologia de Alimentos da UFSJ/CSL.

\subsection{Análises físico-químicas}

Para todas as análises, as amostras foram previamente trituradas em mixer (Mondial M13 Turbo Max/Bahia). Em seguida, foram realizadas análises de $\mathrm{pH}$, acidez titulável e as determinações dos teores percentuais de gordura, extrato seco total, umidade, gordura no extrato seco e proteínas em todas as amostras (Brasil, 2006). As análises físico-químicas seguiram os procedimentos descritos por Brasil (2006) e foram realizadas no Laboratório de Análise de Alimentos da UFSJ/CSL.

\subsection{Análises estatísticas}

O experimento foi conduzido segundo delineamento experimental inteiramente casualizado, com três repetições, com os tratamentos dispostos em esquema de parcelas subdivididas. A parcela foi constituída pelo fator revestimento (presença/ausência) e a subparcela pelo fator tempo de maturação (4, 14 e 22 dias).

Os pressupostos do modelo estatístico, normalidade e homogeneidade, foram analisados pelos testes Shapiro Wilk e Levene, respectivamente. O fator revestimento foi analisado via teste F e o fator tempo pela regressão. As variáveis que não atenderam os pressupostos de normalidade e homocedasticidade, foram analisadas via teste não paramétrico de MannWhitney-Wilcoxon para comparar as medianas das amostras controle e tratamento, dentro de cada tempo separadamente. As análises estatísticas foram realizadas com auxílio do software $\mathrm{R}$ (Team, 2016), adotando o nível de significância de $5 \%$.

\section{RESULTADOS E DISCUSSÕES}

\subsection{Produção do revestimento comestível e definição do dia de aplicação no QMA}

A partir de pré-testes, definiu-se que o revestimento com melhor aspecto e adesão aos queijos foi o preparado com as seguintes quantidades: $3 \% \mathrm{~m} / \mathrm{m}$ de fécula de mandioca , $3 \% \mathrm{~m} / \mathrm{m}$ de glicerina e $94 \% \mathrm{~m} / \mathrm{m}$ do extrato hidrossolúvel de sorgo. O quarto dia de maturação do QMA foi definido como o de melhor eficiência para aplicação do revestimento comestível, pois queijos com menos de quatro dias de maturação dessoram em grande quantidade e fazem com que se solte o revestimento aplicado. Queijos com mais dias de maturação, por terem formação de sua casca já iniciada, não apresentaram boa adesão ao revestimento.

\subsection{Análises microbiológicas}

Não houve diferença estatística entre as amostras controle (queijos que não receberam o revestimento comestível) e tratamento (queijos que receberam o revestimento comestível), dentro de cada tempo e de modo separado $(p>0,05)$. 
As análises exigidas pela legislação vigente para micro-organismos não desejáveis estão apresentadas na Tabela 1 (Brasil, 1996; Minas Gerais, 2002; Minas Gerais, 2008).

Tabela 1: Parâmetros microbiológicos estabelecidos pelo decreto $n^{\circ} 44.864$, para inspeção de queijo Minas artesanal, e determinados pela Portaria N¹46, para queijos industrializados de média umidade (36 \% a 45,9\%)

\begin{tabular}{ccc}
\hline Parâmetros microbiológicos* & \multicolumn{2}{c}{ Critérios de Inspeção } \\
\cline { 2 - 3 } & $\begin{array}{c}\text { Estadual (Decreto } \\
44.864 / 2008)\end{array}$ & $\begin{array}{c}\text { Federal (Portaria } \\
\text { 146/1996) }\end{array}$ \\
\hline Coliformes a $30^{\circ} \mathrm{C}(\mathrm{NMP} / \mathrm{g})$ & $\mathrm{n}=5 ; \mathrm{c}=2 ; \mathrm{m}=1.000 ; \mathrm{M}=5.000$ \\
Coliformes a $45^{\circ} \mathrm{C}$ (NMP/g) & $\mathrm{n}=5 ; \mathrm{c}=2 ; \mathrm{m}=100 ; \mathrm{M}=500$ \\
Estafilococos coagulase positivo (UFC/g) & $\mathrm{n}=5 ; \mathrm{c}=2 ; \mathrm{m}=100 ; \mathrm{M}=1.000$ \\
Salmonella spp./25g & $\mathrm{n}=5 ; \mathrm{c}=0 ; \mathrm{m}=0$ \\
Listeria spp./25g & $\mathrm{n}=5 ; \mathrm{c}=0 ; \mathrm{m}=0$ \\
\hline
\end{tabular}

* Plano de amostragem (n; c; m; M), segundo Brasil (2001). No caso de amostra indicativa, limite maior é o valor representado por M. Fontes: Brasil (1996); Minas Gerais (2008).

Vale ressaltar que, para fiscalização de produtos disponibilizados no mercado/prontos para oferta ao consumidor, o Ministério da Saúde, por meio da Agência Nacional de Vigilância Sanitária estabeleceu padrões microbiológicos para queijos (RDC $N^{\circ} 12$ de Janeiro de 2001), exigindo avaliações de: Coliformes a $45^{\circ} \mathrm{C}(/ \mathrm{g})$, Estafilococos coagulase positiva (/g), Salmonella (/25g) e Listeria monocytogenes (/25g) (Brasil, 2001). Esta Resolução foi atualizada e, em 2019, foram publicadas as novas diretrizes para os padrões microbiológicos para queijos (RDC No $331 \mathrm{e}$ IN NN 60, ambas de 23 de dezembro de 2019), que exigirão avaliações de: enterotoxinas estafilocócicas (ng/g), Salmonella (/25g), Estafilococos coagulase positiva (/g), Escherichia coli (/g) e Bolores e Leveduras (/g). Esta legislação entrará em vigor em dezembro de 2020 (Brasil, 2019a; Brasil, 2019b).

A Tabela 2 apresenta as medianas e os valores máximos e mínimos para os parâmetros avaliados nos queijos controle e tratamento. Os resultados obtidos foram comparados com a legislação vigente, determinando se os queijos estavam adequados ou não para o consumo nos diferentes tempos de maturação. Embora no trabalho, o estudo tenha sido realizado com 60 \% das propriedades cadastradas no Instituto Mineiro de Agropecuária, sendo 3 em um total de 5 propriedades, a amostragem é considerada indicativa e para tal, o valor de comparação para as análises realizadas será a mediana de cada atributo observado na Tabela 2 e os valores representados pela letra $\mathrm{M}$, demonstrados na Tabela 1.

Tabela 2: Medianas, valores mínimo e máximo dos resultados de parâmetros microbiológicos de amostras de queijo Minas artesanal do grupo controle e do tratamento com revestimento comestível a base de fécula de mandioca e extrato aquosos de pericarpo de sorgo submetidos à maturação em temperatura ambiente

\begin{tabular}{|c|c|c|c|c|c|}
\hline \multirow[b]{3}{*}{$\begin{array}{c}\text { Parâmetros } \\
\text { microbiológicos }\end{array}$} & \multirow[b]{3}{*}{ Grupo } & \multicolumn{3}{|c|}{ Maturação } & \multirow[b]{3}{*}{$\begin{array}{c}\text { Aptidão para } \\
\text { consumo }\end{array}$} \\
\hline & & \multicolumn{3}{|c|}{4 dias } & \\
\hline & & Mediana & Mínimo & Máximo & \\
\hline Coliformes a $30^{\circ} \mathrm{C}$ & Controle & $>1100^{a}$ & 1100 & $>1100$ & NC \\
\hline (NMP/g) & Tratamento & $>1100^{a}$ & 1100 & $>1100$ & NC \\
\hline Coliformes a $45^{\circ} \mathrm{C}$ & Controle & $1100^{a}$ & 9,2 & $>1100$ & NC \\
\hline (NMP/g) & Tratamento & $460^{\mathrm{a}}$ & 93 & $>1100$ & $\mathrm{C}$ \\
\hline Estafilococos & Controle & $1,78 \mathrm{E}+04^{\mathrm{a}}$ & $<1000$ & $1,98 E+04$ & NC \\
\hline
\end{tabular}




\begin{tabular}{|c|c|c|c|c|c|}
\hline $\begin{array}{l}\text { coagulase positivo } \\
\text { (UFC/g) }\end{array}$ & Tratamento & $5,94 \mathrm{E}+03^{\mathrm{a}}$ & $<1000$ & $1,72 E+04$ & NC \\
\hline \multirow{2}{*}{$\begin{array}{l}\text { Bolores e leveduras } \\
\text { (UFC/g) }\end{array}$} & Controle & $1,70 E+06^{a}$ & $7,70 E+05$ & $2,32 E+06$ & NA \\
\hline & Tratamento & $2,76 \mathrm{E}+06^{\mathrm{a}}$ & $2,12 E+05$ & $3,29 E+06$ & NA \\
\hline \multirow{2}{*}{$\begin{array}{l}\text { Bactérias ácido láticas } \\
\text { (UFC/g) }\end{array}$} & Controle & $2,00 E+07^{a}$ & $1,64 \mathrm{E}+06$ & $3,20 E+07$ & NA \\
\hline & Tratamento & $3,90 E+07^{a}$ & $9,00 E+06$ & $7,20 E+07$ & NA \\
\hline \multirow[t]{4}{*}{ Salmonella spp. (25g) } & Controle & & Ausência & & $\mathrm{C}$ \\
\hline & Tratamento & & Ausência & & C \\
\hline & & & 14 dias & & \\
\hline & & Mediana & Mínimo & Máximo & $\begin{array}{c}\text { Aptidão para } \\
\text { consumo }\end{array}$ \\
\hline \multirow{2}{*}{$\begin{array}{c}\text { Coliformes a } 30{ }^{\circ} \mathrm{C} \\
\text { (NMP/g) }\end{array}$} & Controle & $75^{a}$ & 15 & $>1100$ & $\mathrm{C}$ \\
\hline & Tratamento & $>1100^{\mathrm{a}}$ & 43 & $>1100$ & $\mathrm{NC}$ \\
\hline \multirow{2}{*}{$\begin{array}{c}\text { Coliformes a } 45^{\circ} \mathrm{C} \\
\text { (NMP/g) }\end{array}$} & Controle & $14^{\mathrm{a}}$ & $<3$ & 210 & $\mathrm{C}$ \\
\hline & Tratamento & $240^{\mathrm{a}}$ & $<3$ & 460 & C \\
\hline \multirow{2}{*}{$\begin{array}{c}\text { Estafilococos } \\
\text { coagulase positivo } \\
\text { (UFC/g) }\end{array}$} & Controle & $<1000^{\mathrm{a}}$ & $<1000$ & $<1000$ & C \\
\hline & Tratamento & $<1000^{a}$ & $<1000$ & $<1000$ & C \\
\hline \multirow{2}{*}{$\begin{array}{l}\text { Bolores e leveduras } \\
\text { (UFC/g) }\end{array}$} & Controle & $1,00 E+07^{a}$ & $7,75 E+04$ & $3,09 E+07$ & NA \\
\hline & Tratamento & $1,19 E+07^{a}$ & $2,40 E+05$ & $2,73 E+07$ & NA \\
\hline \multirow{2}{*}{$\begin{array}{l}\text { Bactérias ácido láticas } \\
\text { (UFC/g) }\end{array}$} & Controle & $4,30 E+07^{a}$ & $3,15 E+07$ & $5,61 E+07$ & NA \\
\hline & Tratamento & $7,60 \mathrm{E}+07^{\mathrm{a}}$ & $2,11 E+07$ & $1,32 E+08$ & NA \\
\hline \multirow[t]{4}{*}{ Salmonella spp. (25g) } & Controle & & Ausência & & $\mathrm{C}$ \\
\hline & Tratamento & & Ausência & & C \\
\hline & & & 22 dias & & \\
\hline & & Mediana & Mínimo & Máximo & $\begin{array}{l}\text { Aptidão para } \\
\text { consumo }\end{array}$ \\
\hline \multirow{2}{*}{$\begin{array}{c}\text { Coliformes a } 30^{\circ} \mathrm{C} \\
\text { (NMP/g) }\end{array}$} & Controle & $43^{\mathrm{a}}$ & $<3$ & 43 & $\mathrm{C}$ \\
\hline & Tratamento & $21^{\mathrm{a}}$ & $<3$ & 93 & C \\
\hline \multirow{2}{*}{$\begin{array}{c}\text { Coliformes a } 45^{\circ} \mathrm{C} \\
\text { (NMP/g) }\end{array}$} & Controle & $<3^{\mathrm{a}}$ & $<3$ & 3,6 & C \\
\hline & Tratamento & $6,2^{\mathrm{a}}$ & $<3$ & 9,2 & C \\
\hline \multirow{2}{*}{$\begin{array}{c}\text { Estafilococos } \\
\text { coagulase positivo } \\
\text { (UFC/g) }\end{array}$} & Controle & $<1000^{\mathrm{a}}$ & $<1000$ & $<1000$ & C \\
\hline & Tratamento & $<1000^{\mathrm{a}}$ & $<1000$ & $<1000$ & C \\
\hline \multirow{2}{*}{$\begin{array}{l}\text { Bolores e leveduras } \\
\text { (UFC/g) }\end{array}$} & Controle & $1,60 E+06^{a}$ & $9,50 E+03$ & $3,00 E+06$ & NA \\
\hline & Tratamento & $1,89 \mathrm{E}+06^{\mathrm{a}}$ & $1,61 E+05$ & $2,05 E+07$ & NA \\
\hline \multirow{2}{*}{$\begin{array}{l}\text { Bactérias ácido láticas } \\
\text { (UFC/g) }\end{array}$} & Controle & $1,35 \mathrm{E}+07^{\mathrm{a}}$ & $1,23 E+07$ & $2,65 E+07$ & NA \\
\hline & Tratamento & $1,30 \mathrm{E}+07^{\mathrm{a}}$ & $8,53 E+06$ & $1,56 \mathrm{E}+07$ & NA \\
\hline \multirow[t]{2}{*}{ Salmonella spp. (25g) } & Controle & & Ausência & & C \\
\hline & Tratamento & & Ausência & & $\mathrm{C}$ \\
\hline
\end{tabular}

Medianas seguidas pela mesma letra não diferem entre si, para as análises nas amostras controle e tratamento, pelo teste de Mann-Whitney-Wilcoxon, a 5 \% de significância. Legenda "Aptidão par consumo": C - Conforme; NC - Não Conforme; NA - Não se Aplica

A presença de populações de micro-organismos em queijo pode ser dividida em duas categorias: micro-organismos desejáveis e indesejáveis, subdivididos por sua vez em deteriorantes ou patogênicos (Oliveira, 2014). Os derivados de leite, principalmente os queijos, 
são alimentos altamente nutritivos, ideais para o crescimento dos micro-organismos desejáveis e indesejáveis (Dores, 2007).

Uma das principais desvantagens dos queijos artesanais, feitos a partir de leite cru, é a possível presença de patógenos como Salmonella spp., Escherichia coli e Staphylococcus aureus, que são alguns exemplos de micro-organismos associados a surtos de infecções e intoxicações alimentares (Oliveira, 2014).

Durante a produção do queijo Minas artesanal, algumas etapas como a prensagem manual, o processo de salga, viragem e lavagem durante a maturação necessitam de constante manipulação e, com isso, tornam o queijo propício a contaminação, especialmente de origem microbiológica (Pinto et al., 2009). Porém, alguns cuidados devem ser seguidos para tornar estes queijos seguros, atuando no controle da microbiota indesejável. Deve-se ressaltar a qualidade da matéria-prima, a temperatura e tempo de maturação, a aplicação das Boas Práticas de Fabricação (BPF) e a presença de uma microbiota endógena rica em bactérias láticas, que irão competir com os micro-organismos indesejáveis (Pinto et al., 2009; Dores \& Ferreira, 2012). Além disso, o uso de Boas Práticas Agropecuárias, que envolvem controle sanitário do rebanho, uso de água potável, saúde dos envolvidos na cadeia de produção do queijo, entre outros fatores, são essenciais para a produção de um produto inócuo (Minas Gerais, 2018a; Minas Gerais, 2018b; Brasil, 2019c).

De acordo com a Tabela 2, no quarto dia de maturação não é possível estimar com precisão se os coliformes a $30^{\circ} \mathrm{C}$ estão abaixo do valor máximo permitido pela legislação ( $M=5000)$, uma vez que não consegue-se definir o quanto o valor máximo está maior que 1100 $\mathrm{NMP} / \mathrm{g}$, para os queijos controle e tratamento. No décimo quarto dia de maturação, também não é possível confirmar se os queijos estão seguros para o consumo, porém, se observados os valores mínimos para este parâmetro microbiológico, os mesmos apontam estarem mais próximos de $1100 \mathrm{NMP} / \mathrm{g}$ que do valor máximo permitido pela legislação de $5000 \mathrm{NMP} / \mathrm{g}$. Os queijos com 22 dias de maturação apresentaram valores máximos dentro do permitido, sendo considerados aptos para consumo, como ocorre atualmente. Na análise dos coliformes a $45{ }^{\circ} \mathrm{C}$, apenas os queijos controle com quatro dias de maturação apresentaram valores que os caracterizaram como impróprios para consumo. Nos demais períodos, os queijos controle e tratamento já seriam considerados apropriados para o consumo. Embora sem diferença estatística $(p>0,05)$ durante todo o período de maturação, o queijo tratado com revestimento comestível apresentou mediana razoavelmente menor se comparado com o queijo controle, ao final de 22 dias de maturação, quanto à análise de coliformes a $30^{\circ} \mathrm{C}$. Já para os coliformes a 45 ${ }^{\circ} \mathrm{C}$, apenas com 4 dias maturação a mediana de UFC/g do queijo tratado mostrou-se menor.

Oliveira (2014) reportou, em trabalho realizado com QMA na mesma região, valores médios de $6407 \mathrm{NMP} / \mathrm{g}$ para coliformes a $30^{\circ} \mathrm{C}$ e $5545 \mathrm{NMP} / \mathrm{g}$ para coliformes a $45^{\circ} \mathrm{C}$. Castro et al. (2016) encontraram contagem média igual a $9417 \mathrm{NPM} / \mathrm{g}$ e $5645 \mathrm{NMP} / \mathrm{g}$, para contagem de coliformes a $30^{\circ} \mathrm{C}$ e a $45^{\circ} \mathrm{C}$, respectivamente, ambas no período chuvoso e em estudo realizado com QMA no Campo das Vertentes. Os coliformes a $30^{\circ} \mathrm{C}$ em altas contagens são responsáveis pela deterioração do queijo e podem levar a um defeito clássico chamado estufamento precoce, em que bactérias da família Enterobacteriaceae, ao fermentarem a lactose, produzem $\mathrm{CO}_{2}$ e $\mathrm{H}_{2}$, com formação de bolhas pequenas e consequente abaulamento do produto (Oliveira, 2014). Este 
defeito é observado entre o processo de elaboração e o processo de salga do queijo, sendo perceptível logo nas primeiras 24 horas de produção (Castro, 2015). Durante a coleta das amostras, não foi observada nenhuma peça de queijo que continha características de estufamento. Somado a isso, a não observância de crescimento intenso de coliformes Totais pode indicar boas práticas de fabricação das queijarias participantes deste estudo, durante a elaboração e o armazenamento dos queijos. A queda do número de coliformes a $30^{\circ} \mathrm{C}$ durante o período de maturação indica, também, que não houve recontaminação após processamento.

A presença de coliformes a $45{ }^{\circ} \mathrm{C}$ pode estar associada a material de origem fecal e falhas no controle de higienização no processo de produção do queijo Minas artesanal. A diminuição destes parâmetros nas amostras avaliadas durante a maturação mostra que houve um controle higiênico-sanitário adequado durante todo o processamento e armazenamento e/ou houve ação das bactérias ácido-láticas, que competem pelos substratos, produzem substâncias antimicrobianas, entre outros fatores, e são importantes na inibição de coliformes Termotolerantes e outros patógenos.

Quanto às contagens de Estafilococos coagulase positivo, apenas os queijos oriundos do quarto dia de maturação não apresentaram conformidade de acordo com a legislação, com contagens máximas de $1,98 \times 10^{4} \mathrm{UFC} / \mathrm{g}$ e $1,72 \times 10^{4} \mathrm{UFC} / \mathrm{g}$ para os queijos controle e tratamento, respectivamente. Nos demais dias de análise, as amostras estavam conforme determina a legislação. Oliveira (2010) encontrou contagens superiores a $10^{7} \mathrm{UFC} / \mathrm{g}$ de Staphylococcus spp. em queijo Minas artesanal da região de Campo das Vertentes. Em seu estudo, também na mesma microrregião, Oliveira (2014) reportou valores médios de Estafilococos coagulase positivo de 2,6 × 104 UFC/g para o período da seca e de $1,1 \times 10^{5} \mathrm{UFC} / \mathrm{g}$ no período chuvoso. Os queijos que receberam o tratamento com revestimento comestível de fécula de mandioca e extrato aquoso de farinha de pericarpo de sorgo apresentaram contagem inferior aos queijos controle, quando comparados aos 4 dias de maturação. Durante o restante da maturação, a mediana para ambos os tratamentos apresentou-se igual.

A existência de Staphylococcus spp. em contagens superiores a $10^{4} \mathrm{UFC} / \mathrm{g}$ é alarmante devido a probabilidade de produção de enterotoxinas no alimento. Apesar de a legislação determinar parâmetros de aceitação no queijo apenas para Estafilococos coagulase positivo, é conhecido que algumas amostras coagulase negativo, incluídas nesta contagem total de Staphylococcus spp., são também produtoras de enterotoxinas, caracterizando um risco potencial a saúde do consumidor (Castro, 2015).

Todas as amostras, controle e tratamento, de todos os dias de maturação avaliados, apresentaram ausência de Salmonella spp.. Resultado semelhante foi obtido em outro trabalho realizado com queijo Minas artesanal no Campo das Vertentes (Oliveira, 2014). Dores et al. (2013) também verificaram ausência desse micro-organismo em suas amostras de queijo Minas artesanal da Serra da Canastra. A ausência de contaminação por este micro-organismo nas matérias-primas utilizadas, o cuidado com a manipulação adequada do queijo e as prevenções contra as contaminações cruzadas são explicações para ausência relatada neste e em diversos trabalhos (Castro, 2015). 
Os valores medianos de contagem total de bolores e leveduras nos queijos ao longo do período de maturação, controle e tratamento, foram na ordem de $10^{6}$ a $10^{7} \mathrm{UFC} / \mathrm{g}$. Sem diferença significativa ( $p>0,05$ ), os queijos tratamento apresentaram medianas próximas aos queijos controle durante todo o período de maturação. Vale ressaltar que não há padrão legal que quantifique um limite mínimo ou máximo para esses micro-organismos em queijo Minas artesanal (Oliveira, 2014). Castro et al. (2016) encontrou valores médios de contagem de bolores e leveduras em queijo Minas artesanal do Campo das Vertentes de 1,1 x 107 UFC/g no período da seca e 1,4 x $10^{6} \mathrm{UFC} / \mathrm{g}$ no período da chuva. Em contagem de bolores e leveduras em queijo Minas artesanal da Serra da Canastra, foram encontrados valores entre $2,5 \times 10^{3}$ e 7,9 $\times 10^{7}$ UFC/g (Borelli et al., 2006). Em queijo Minas artesanal elaborado em queijarias não cadastradas na região da Canastra, altas contagens de bolores e leveduras foram relatadas, cuja média foi de $1,2 \times 10^{8} \mathrm{UFC} / \mathrm{g}$ (Resende, 2010).

A presença de bolores e leveduras em queijos Minas artesanal é frequentemente observada devido as condições não controladas em que o queijo permanece, principalmente durante a maturação, pois estes micro-organismos podem se desenvolver em paredes e prateleiras da queijaria. Embora não exista limite específico para estes micro-organismos, seu controle é importante para preservar as características físico-químicas e sensoriais dos queijos, especialmente por sua presença visível nos queijos não ser apreciada por alguns consumidores. Deste modo, alguns produtores fazem escovação ou toilet das peças para retirada dos bolores e leveduras que aparecem na sua casca. Neste trabalho, foi sugerido aos produtores que não fizessem a toilet dos queijos, de modo que fosse possível avaliar a capacidade do revestimento comestível como antimicrobiano. Porém, alguns produtores relataram que fizeram a escovação de algumas peças por dificuldade de controlar posteriormente a presença de fungos na queijaria, que poderia atingir e comprometer toda a produção, além da utilizada no estudo.

A alta contagem observada nos queijos durante o período de maturação pôde ser observada na Tabela 2, no decorrer do experimento. Um dos produtores passara por modificações na estrutura da queijaria, tais como aumento da dimensão de uma janela e troca completa do telhado, e relatou dificuldades em controlar estes micro-organismos. Com isso, alguns queijos chegaram a apresentar bolores e leveduras por toda a superfície da casca do queijo. Apesar disso e do relatado anteriormente sobre a toilet de algumas peças, as contagens medianas de bolores e leveduras foram próximas, sem diferença estatística. Contagens elevadas de bolores e leveduras podem ser associadas a presença de bactérias ácido láticas que, quando em grande proporção, atuam na fermentação da lactose dos queijos, produzindo ácido lático. 0 ácido lático atua inibindo grande parte das bactérias, até mesmo patogênicas, e propiciam o desenvolvimento de bolores e leveduras, uma vez que são mais resistentes e tolerantes a ambientes ácidos.

Estudos para a identificação destes fungos são necessários, uma vez que tradicionalmente eles são encontrados nas queijarias e nos produtos. Ultimamente, tem-se verificado uma mudança de comportamento dos consumidores e uma crescente valorização dos queijos mofados. Contudo, ainda não é conhecido o papel que os fungos podem desempenhar, seja desejável,por exemplo, nas características sensoriais e flavour do queijo, ou indesejável, tais como deteriorações e produção de micotoxinas. Ressalta-se que já existem pesquisas em 
andamento para identificar os fungos presentes no queijo Minas artesanal, com intuito de descobrir o papel destes fungos no organismo humano, mas que ainda não foram publicadas.

As contagens de bactérias ácido-láticas mantiveram-se constantes durante todo o tempo de maturação do queijo Minas artesanal do Campo das Vertentes, apresentando contagens medianas de $10^{7} \mathrm{UFC} / \mathrm{g}$ para o queijo controle e para o tratamento. Os queijos tratamento apresentaram medianas de UFC/g superiores aos queijos controle aos 4 e 14 dias de maturação, podendo indicar favorecimento às bactérias ácido-láticas, embora sem diferença estatística entre os tratamentos $(p>0,05)$. Ao final de 22 dias de maturação, as medianas de UFC/g para as bactérias ácido-láticas apresentaram menor diferença entre as amostras. Oliveira (2014) reportou, para BAL em meio MRS, a grandeza de $1,6 \times 10^{8} \mathrm{UFC} / \mathrm{g}$. Castro et al. (2016) encontraram valor médio de 3,2 × $10^{8} \mathrm{UFC} / \mathrm{g}$ no período chuvoso, em trabalho realizado no Campo das Vertentes. Santos (2010) ao analisar bactérias ácido-láticas em queijo Minas artesanal do Serro, durante nove semanas, maturado à temperatura ambiente, relatou que a média encontrada na primeira semana de maturação foi de 7,9 × 107 UFC/g. Em estudo realizado na região da Serra da Canastra, em propriedades não cadastradas, a contagem de bactérias ácidoláticas em queijo Minas artesanal foi de 3,0 x 107 UFC/g no meio MRS (Resende et al., 2011), o mesmo utilizado neste trabalho.

Bactérias ácido-láticas são micro-organismos responsáveis pela fermentação e transformação do leite em queijo, sendo, portanto, desejáveis. Elas formam um grupo altamente heterogêneo, cujos membros são capazes de produzir ácido lático a partir de hexoses (Oliveira, 2014). Além de converter carboidratos em ácido lático, as bactérias ácido-láticas são responsáveis por produzir metabólitos secundários que são responsáveis pela criação de odores e sabores, dando características diferenciadas em produtos lácteos, especialmente os queijos. Também são capazes de sintetizar bacteriocinas, peptídeos com atividades antagonistas contra patógenos encontrados em alimentos, como Salmonella spp., Listeria monocytogenes e Clostridium botulinum (Ross et al., 2002; Perin et al., 2012). Sant'Anna et al. (2017), avaliando o potencial probiótico de bactérias ácido-láticas isoladas de queijo Minas artesanal do Campo das Vertentes, obtiveram resultados promissores contra Salmonella Typhimurium. Assim, a presença de altas concentrações de bactérias ácido-láticas, tais como as evidenciadas no presente estudo, confere sabores e aromas característicos nos queijos artesanais, além de poder atuar como inibidor de micro-organismos indesejáveis a partir da produção de ácido lático, tornando o meio seletivo, e pela produção de substâncias que inibem o desenvolvimento e manutenção da microbiota patógena e deteriorante.

Embora não tenha havido diferença estatística entre as amostras controle e tratamento ao longo do período avaliado, a maturação mostrou ser de suma importância para controle dos micro-organismos patógenos. Assim, apesar do anseio da população em consumir queijos mais frescos, a maturação contribui para aumentar a contagem de bactérias ácido-láticas, tornando o produto mais seguro para consumo. 


\subsection{Análises físico-químicas}

Não houve diferença significativa $(p>0,05)$ entre os fatores revestimento e tempo de maturação, indicando que as amostras sofreram interferência dos fatores de forma independente, e que a junção de tais parâmetros não afetou o resultado do experimento, para todas as análises físico-químicas estudadas.

A Tabela 3 retrata os valores médios para as análises físico-químicas realizadas. Não houve diferença estatística entre as amostras controle e tratamento.

Os valores médios da medida de $\mathrm{pH}$ foram de 5,2 para as amostras controle e 5,1 para as amostras submetidas ao tratamento com revestimento. Foi possível observar que, embora o extrato do pericarpo de sorgo que constitui o revestimento tenha sido preparado em água acidificada com ácido cítrico, não houve alteração significativa na média de pH dos queijos.

Tabela 3: Valores médios dos atributos físico-químicos de amostras queijo Minas artesanal do grupo controle e tratamento com revestimento comestível a base de fécula de mandioca e extrato aquoso de pericarpo de sorgo submetidos a um período de maturação em temperatura ambiente

\begin{tabular}{cccccccc}
\hline Grupo & pH & $\begin{array}{c}\text { Acidez } \\
\text { Titulável }\end{array}$ & $\begin{array}{c}\text { Gordura } \\
\text { (\%) }\end{array}$ & $\begin{array}{c}\text { Extrato } \\
\text { Seco } \\
\text { (\%) }\end{array}$ & $\begin{array}{c}\text { Umidade } \\
\text { (\%) }\end{array}$ & $\begin{array}{c}\text { Gordura no } \\
\text { Extrato } \\
\text { Seco (\%) }\end{array}$ & $\begin{array}{c}\text { Proteínas } \\
\text { (\%) }\end{array}$ \\
\hline Controle & $5,2^{\mathrm{a}}$ & $1,3^{\mathrm{a}}$ & $30,9^{\mathrm{a}}$ & $66,0^{\mathrm{a}}$ & $34,0^{\mathrm{a}}$ & $46,8^{\mathrm{a}}$ & $22,6^{\mathrm{a}}$ \\
Tratamento & $5,1^{\mathrm{a}}$ & $1,2^{\mathrm{a}}$ & $31,4^{\mathrm{a}}$ & $66,2^{\mathrm{a}}$ & $33,8^{\mathrm{a}}$ & $47,1^{\mathrm{a}}$ & $23,0^{\mathrm{a}}$ \\
\hline
\end{tabular}

Médias seguidas de mesma letra na coluna não diferem entre si pelo teste $F$, a $5 \%$ de significância.

Segundo Oliveira (2014), embora ocorra acidificação inicial da matriz do queijo pela ação de bactérias ácido-láticas, ao longo da maturação ocorre degradação de proteínas devido a presença de proteases naturais do leite e das próprias BAL, fazendo com que o pH aumente razoavelmente, como observado.

Júnior et al. (2014), em estudo que avaliaram as características do queijo Minas artesanal do Campo das Vertentes com 10, 20 e 30 dias de maturação nos períodos de seca e chuva, encontraram valores de $\mathrm{pH}$ que variaram entre 5,0 e 5,4. Oliveira (2010) encontrou valor médio de $\mathrm{pH}$ de 6,04 em queijo Minas artesanal da mesma região. O valor máximo encontrado em seu estudo foi de 7,53, muito acima dos valores de $\mathrm{pH}$ de outros estudos realizados naquela e nas demais regiões produtoras de queijo Minas artesanal. Em pesquisa com queijo Minas artesanal da Serra da Canastra, os valores de pH ficaram entre 4,9 e 5,1 (Dores et al., 2013).

A média de acidez titulável do queijo Minas artesanal, expressada em porcentagem de ácido lático, foi de 1,3\% para o queijo controle e de 1,2 \% para o queijo tratamento, não apresentando entre si diferença significativa $(p>0,05)$. Valores inferiores de acidez titulável para queijos Minas artesanais da região da Serra da Canastra, Serro e Cerrado foram reportados, com médias de acidez de 0,48 \%, 0,46 \% e 0,40 \%, respectivamente. Contudo, sem diferença estatística $(p>0,05)$ entre as regiões avaliadas (Oliveira et al., 2013). Em estudo realizado por Martins (2006) na região do Serro, a acidez titulável em dois períodos distintos de produção 
apresentou médias de 0,9\% a 1,04\%, expressos em ácido lático, comumente utilizado para determinação de acidez em produtos lácteos, e também utilizado como referência neste estudo.

Durante a maturação, ocorre degradação da lactose, resultado da fermentação e metabolização deste substrato, e consequente produção de ácido lático por meio da ação das bactérias ácido-láticas. Dessa forma, é possível observar um leve aumento na porcentagem de ácido lático nos queijos com o passar dos dias de maturação. A presença maior ou menor de ácido lático pode ser também influenciada pela quantidade de "pingo" utilizado na produção dos queijos, bem como a utilização de "pingos" mais ácidos.

As amostras de queijo Minas artesanal controle apresentaram valor médio de teor de gordura de 30,9 \%, não diferindo estatisticamente das amostras de queijo adicionado de revestimento comestível elaborado a partir de fécula de mandioca e de extrato aquoso de pericarpo de sorgo, com teor médio de gordura de 31,4 \% ( $p>0,05)$. Valores diferentes foram reportados por Costa Junior et al. (2009) em trabalho realizado com queijo Minas artesanal da Serra da Canastra, na grandeza de 27,6 \% de gordura no verão, e de 21,8 \% de gordura no inverno. Em trabalho realizado no Campo das Vertentes, a porcentagem de gordura nos queijos foi $33,4 \%$, no período seco, e de $34,1 \%$, no período chuvoso, em queijos de até 30 dias de maturação (Moreno, 2013). De acordo com Castro (2015), o teor de gordura do queijo está diretamente relacionado ao teor de gordura do leite; porém, pode sofrer influência de fatores como o teor de umidade do queijo, tempo de maturação e presença de micro-organismos lipolíticos no alimento.

Moreno (2013), em estudo sobre a caracterização física e físico-química de queijo Minas artesanal do Campo das Vertentes com 10, 20 e 30 dias de maturação, encontrou valores médios de gordura de $33,4 \%$ no período seco e 34,1 \% no período chuvoso, ficando próximo dos valores encontrados neste estudo. Valores médios próximos, de 32,82 \% no período da seca e 38,51 \% no período chuvoso, também foram reportados em estudo feito por Oliveira (2014).

Neste trabalho foram encontrados teores médios de extrato seco total de 66,0 \% e 66,2 \% para os queijos controle e tratamento, respectivamente. Estudos mostram que os resultados encontrados foram menores que resultados encontrados para queijo Minas artesanal das regiões do Serro, da Canastra e do Cerrado de 52,18 \%, 52,8 \% e 51,77 \%, respectivamente (Oliveira et al., 2013). Oliveira (2014) relatou valores médios de extrato seco total de 60,55 \% na seca e 63,17 \% no período chuvoso e segundo o autor, a variação dos índices de extrato seco total está relacionada a fatores como técnicas de corte, dessoragem da massa e compactação durante a elaboração dos queijos. Moreno (2013) encontrou valor médio mais próximo aos encontrados neste estudo, na grandeza de $64,2 \%$.

Detectou-se neste estudo valores médios de umidade que não estão de acordo com o padrão definido pela legislação estadual, classificando os queijos como sendo de baixa umidade (Brasil, 1996; Minas Gerais, 2008).

O teor de umidade está diretamente relacionado com o corte, dessoragem e compactação da massa durante a produção do queijo. Acrescentam-se ainda o local e a banca de madeira utilizados na maturação, além de fatores intrínsecos dos queijos, como a atividade de água. O tamanho do queijo é determinante para a rapidez da perda de umidade, uma vez que 
queijos maiores concentram umidade em seu interior por um período de tempo maior (Martins, 2006). Oliveira et al. (2013) reportou valores umidade média de $47,83 \%, 44,90 \%$ e 46,50 \%, em queijos Minas artesanais das microrregiões do Serro, Serra da Canastra e Cerrado, respectivamente.

A importância da determinação do teor de umidade está relacionada principalmente com a presença e desenvolvimento de micro-organismos. Por se tratar de uma matriz rica em substratos e com considerável umidade, o queijo constitui um ambiente propício para microorganismos, patógenos ou não. A maturação contribui de forma significativa para reduzir este índice, tornando o queijo Minas artesanal mais seguro para os consumidores. Espera-se que na fase inicial, os queijos apresentem umidade maior e conforme a maturação ocorre, esta variável tende a diminuir. Assim, a queda de umidade durante a maturação colabora para concentração dos constituintes do queijo e, juntamente com a produção de ácido lático, tornam o produto apreciado devido ao sabor e ao aroma característicos, formados neste processo.

Os teores médios de gordura no extrato seco (GES) tanto para as amostras controle quanto para as amostras tratamento, caracterizaram os queijos como gordos, de acordo com a legislação federal (Brasil, 1996). Castro (2015) encontrou médias de porcentagem de GES 56,81\% no período chuvoso em análise de amostras de queijos do Campo das Vertentes, em queijos com um dia de maturação, justificando o alto valor encontrado. Oliveira (2010) relatou em sua pesquisa valores médios mais próximos para queijos da mesma mesorregião, na ordem de 47,68 $\%$.

A Tabela 3 apresenta os valores médios dos teores de proteínas para as amostras de queijo controle $(22,6 \%)$ e tratamento (23,0 \%). Valor próximo foi reportado por Moreno (2013) em análise de queijo Minas artesanal do Campo das Vertentes, que encontrou valores de 24,10\% de proteína no queijo produzido no período chuvoso e de $22,57 \%$ de proteína no queijo produzido no período seco. Oliveira et al. (2013) demonstrou valores médios de proteínas de $14,08 \%, 18,51 \%$ e 14,55 \% nas microrregiões do Serro, Serra da Canastra e Cerrado, respectivamente.

Mesmo que não tenha sido observado diferença significativa $(p>0,05)$ para todas as análises físico-químicas, é plausível afirmar que o revestimento comestível apresente caráter hidrofílico devido a presença da fécula de mandioca. Porém, o uso de plastificante tende a tornálo menos susceptível a troca de vapor de água com o meio ambiente. Ainda assim, é possível observar que os queijos tratamento apresentaram menor valor para umidade e maior valor para extrato seco, quando comparado às amostras controle, indicando que o revestimento foi vulnerável à perda de água, ou seja, é permeável à troca de vapor de água. Por outro lado, observou-se pequena diferença a mais nas análises de gordura, gordura no extrato seco e proteínas em favor dos queijos tratamento, podendo indicar caráter lipofílico e afinidade por proteínas por parte dos componentes do extrato aquoso da farinha de pericarpo de sorgo.

\section{CONCLUSÕES}

A produção do extrato aquoso de pericarpo de sorgo $94 \% \mathrm{~m} / \mathrm{m}, 3 \% \mathrm{~m} / \mathrm{m}$ de fécula de mandioca e $3 \% \mathrm{~m} / \mathrm{m}$ de glicerina foi a mais eficaz na elaboração do revestimento comestível. A 
aplicação do revestimento comestível no quarto dia de maturação do QMA foi bem sucedida, pois houve boa adesão na superfície dos queijos.

Não houve diferença estatística entre os parâmetros microbiológicos avaliados para os queijos controle e tratamento. Com exceção de coliformes a $30^{\circ} \mathrm{C}$, todos os resultados das demais análises exigidas podem considerá-lo apto para consumo aos 14 dias de maturação, de acordo com legislação vigente, indicando possibilidade de redução do tempo de maturação. Todas as amostras tenderam a apresentar altas contagens medianas de bactérias ácido-láticas, responsáveis para dar sabor e aroma característicos para o queijo Minas artesanal, além de contribuir na inibição de micro-organismos indesejáveis.

Não houve diferença estatística entre os parâmetros físico-químicos avaliados para os queijos controle e tratamento. Pelos resultados médios apresentados, o queijo Minas artesanal do Campo das Vertentes foi classificado como gordo e de baixa umidade.

Estudos futuros são necessários para potencializar o uso de revestimentos comestíveis que contenham ingredientes com funções antimicrobianas e funcionais. Deve-se pesquisar novas formas de produção do revestimento que não envolvam ação do calor, para preservação dos atributos funcionais, e outras opções de matrizes, além da fécula de mandioca, que façam com que o revestimento comestível tenha melhor e maior adesão aos queijos e/ou outros alimentos que se encaixem neste contexto. O sorgo continua a ser uma interessante opção para estes revestimentos devido às suas propriedades, podendo ser melhor explorado e incorporado na alimentação humana.

\section{AGRADECIMENTOS}

À Fundação de Amparo à Pesquisa do Estado de Minas Gerais/FAPEMIG, por meio da PróReitoria de Pesquisa/PROPE-UFSJ, pelo fornecimento da bolsa de iniciação científica; aos técnicos Rafael de Araújo Miguel (EMBRAPA Milho e Sorgo) e Edimilson Tinoco Vilela Júnior (UFSJ), por todo auxílio laboratorial; aos produtores das queijarias, pelo interesse na pesquisa e pelo acolhimento; aos professores que aconselharam e cederam os laboratórios para o desenvolvimento de toda a pesquisa, e aos amigos, pelo auxílio no preparo e na execução das análises.

\section{REFERÊNCIAS}

Awika, J. M., \& Rooney, L. W. (2004). Sorghum phytochemicals and their potential impact on human health. Phytochemistry, 65(9), 1199-1221.

Barbosa, M. P., \& Queiroz, V. A. V. (2018). Extração, caracterização química de corante natural de sorgo de genótipo SC 319 e aplicação em bala de goma de gelatina. In Embrapa Milho e Sorgo-Artigo em anais de congresso (ALICE). In: SEMINÁRIO DE INICIAÇÃO CIENTÍFICA PIBIC/BIC JÚNIOR, 13., 2018, Sete Lagoas.[Trabalhos apresentados]. Sete Lagoas: Embrapa Milho e Sorgo, 2018.

Bobbio, P. A., \& Bobbio, F. O. (1992). Química do processamento de alimentos. Livraria Varela. 
Borelli, B. M., Ferreira, E. G., Lacerda, I. C., Franco, G. R., \& Rosa, C. A. (2006). Yeast populations associated with the artisanal cheese produced in the region of Serra da Canastra, Brazil. World Journal of Microbiology and Biotechnology, 22(11), 1115-1119.

Brasil. (2001). Aprova o Regulamento Técnico sobre padrões microbiológicos para alimentos (Resolução RDC no 12, de 2 de janeiro de 2001). Diário Oficial [da] República Federativa do Brasil.

Brasil. (2011). Critérios Adicionais para Elaboração de Queijos Artesanais. (Instrução Normativa ${ }^{\circ}$ 57, 15 de dezembro de 2011). Diário Oficial [da] República Federativa do Brasil.

Brasil. (2019c). Coloca em consulta pública a minuta de IN de Boas Práticas Agropecuárias para concessão do Selo ARTE (Portaria $n^{\circ} 83$ de 10 de setembro de 2019). Diário Oficial [da] República Federativa do Brasil.

Brasil. (2019a). Dispõe sobre os padrões microbiológicos de alimentos e sua aplicação (Resolução da diretoria colegiada no 331 de 23 de dezembro de 2019). Diário Oficial [da] República Federativa do Brasil.

Brasil. (2019b). Estabelece as listas de padrões microbiológicos para alimentos (Instrução Normativa no 60 de 23 de dezembro de 2019) Diário Oficial [da] República Federativa do Brasil.

Brasil. (2006). Oficializa métodos analíticos oficiais físico-químicos, para controle de leite e produtos lácteos (Instrução normativa no 68 de 12 de dezembro de 2006). Diário Oficial [da] República Federativa do Brasil.

Brasil. (1996). Regulamento Técnico de Identidade e Qualidade De Produtos Lácteos (Portaria $\mathrm{n}^{\circ}$ 146 de 07 março de 1996). Diário Oficial [da] República Federativa do Brasil.

Brasil. (2017). Regulamenta a Lei № 1.283, de 18 de dezembro de 1950, e a Lei no 7.889, de 23 de novembro de 1989, que dispõem sobre a Inspeção Industrial e Sanitária de Produtos de Origem Animal. (Decreto no 9.013, de 29 de março de 2017). Diário Oficial [da] República Federativa do Brasil.

Castro, R. D. (2015). Queijo Minas Artesanal fresco de produtores não cadastrados da mesorregião de Campo das Vertentes-MG: qualidade microbiológica e físico-química em diferentes épocas do ano (Doctoral dissertation, Dissertação de Mestrado em Ciência Animal, Universidade Federal de Minas Gerais, Belo Horizonte, MG, Brasil).

Castro, R. D., Oliveira, L. G., Sant'Anna, F. M., Luiz, L. M. P., Sandes, S. H. C., Silva, C. I. F., ... \& Souza, M. R. (2016). Lactic acid microbiota identification in water, raw milk, endogenous starter culture, and fresh Minas artisanal cheese from the Campo das Vertentes region of Brazil during the dry and rainy seasons. Journal of Dairy Science, 99(8), 6086-6096.

Costa Junior, L. C. G., Costa, R. G. B., Magalhães, F. A. R., Vargas, P. I. R., Fernandes, A. J. M., \& Pereira, A. S. (2009). Variações na composição de queijo Minas artesanal da Serra da 
Canastra nas quatro estações do ano. Revista do Instituto de Laticínios Cândido Tostes, 64(371), 13-20.

Dores, M. T. D., Dias, R. S., Arcuri, E. F., Nobrega, J. E. D., \& Ferreira, C. L. D. L. F. (2013). Enterotoxigenic potential of Staphylococcus aureus isolated from Artisan Minas cheese from the Serra da Canastra-MG, Brazil. Food Science and Technology, 33(2), 271-275.

Dores, M. T., \& Ferreira, C. L. D. L. F. (2012). Queijo minas artesanal, tradição centenária: ameaças e desafios. Revista Brasileira de Agropecuária Sustentável, 2(2), 26-34.

Dores, M. T. (2007). Queijo Minas artesanal da Canastra maturado à temperatura ambiente e sob refrigeração (Dissertação de Doutorado, Universidade Federal de Viçosa).

Fai, A. E. C., de Souza, M. R. A., Bruno, N. V., \& Andrade Gonçalves, É. C. B. (2015). Produção de revestimento comestível à base de resíduo de frutas e hortaliças: aplicação em cenoura (Daucus carota L.) minimamente processada. Scientia Agropecuaria, 6(1), 59-68.

IBGE. (2010). Instituto Brasileiro de Geografia e Estatística. Estado de Minas. Meso e microrregiões do IBGE.

IMA. (2009). Instituto Mineiro de Agropecuária. Região do Campo das Vertentes é reconhecida como produtora de Queijo Minas Artesanal. 2009.

Júnior, L. C. G. C., Moreno, V. J., Magalhães, F. A. R., Costa, R. G. B., Resende, E. C., \& Carvalho, K. B. A. (2014). Maturação do Queijo Minas Artesanal da Microrregião Campo das Vertentes e os efeitos dos períodos seco e chuvoso. Revista do Instituto de Laticínios Cândido Tostes, 69(2), 111-120.

Kil, H. Y., Seong, E. S., Ghimire, B. K., Chung, I. M., Kwon, S. S., Goh, E. J., ... \& Yu, C. Y. (2009). Antioxidant and antimicrobial activities of crude sorghum extract. Food Chemistry, 115(4), 1234-1239.

Lemos, A. D. M. (2009). Caracterização da Região dos Campos das Vertentes como produtora de Queijo Minas Artesanal. Campos das Vertentes: Secretaria Municipal de Agricultura e Pecuária de São João del-Rei.

Lopes, A. R., Dragunski, D. C., Caetano, J., Francisco, C. B., \& Júnior, L. F. B. (2018). Conservação de goiabas com revestimentos comestíveis de amido e caseína com extrato de barbatimão. Revista Engenharia na Agricultura, 26(4), 295-305.

Martins, J. M. (2006). Características físico-químicas e microbiológicas durante a maturação do queijo Minas artesanal da região do Serro. 2006. 158f (Doctoral dissertation, Dissertação (Mestrado) Universidade Federal de Viçosa, Viçosa.

Minas Gerais (2008). Decreto $\mathrm{n} 044.864$, de 1 을 de agosto de 2008. Altera o Regulamento da Lei $n$ o 14.185, de 31 de janeiro de 2002, que dispõe sobre o processo de produção de Queijo Minas Artesanal. Belo Horizonte, MG. 
Minas Gerais. (2002). Lei no 14.185, de 31 de janeiro de 2002. Dispõe sobre o processo de produção do Queijo Minas Artesanal e dá outras providências. Belo Horizonte, MG.

Minas Gerais (2012). Lei no 20.549, de 18 de dezembro de 2012. Dispõe sobre a produção e a comercialização dos queijos artesanais de Minas Gerais. Belo Horizonte, MG.

Minas Gerais. (2018a). Lei $\mathrm{n}^{\circ}$ 22.926, de 12 de janeiro de 2018. Programa de Certificação de Produtos Agropecuários e Agroindustriais - Certifica Minas. Instituto Mineiro de Agropecuária. Belo Horizonte, MG.

Minas Gerais. (2014a). Portaria no 1.397, de 13 fevereiro de 2014. Identifica a Microrregião do Triângulo Mineiro como produtora de Queijo Minas Artesanal. Instituto Mineiro De Agropecuária. Belo Horizonte, MG.

Minas Gerais. (2014b). Portaria no 1.428, de 29 agosto de 2014. Identifica a microrregião da Serra do Salitre como produtora do queijo Minas artesanal. Instituto Mineiro De Agropecuária. Belo Horizonte, MG.

Minas Gerais. (2017). Portaria № 1.736, de 27 de julho de 2017. Altera a Portaria no 1305/2013, de 30 de abril de 2013, que dispõe sobre o período de maturação do Queijo Minas Artesanal. Instituto Mineiro De Agropecuária. Belo Horizonte, MG.

Minas Gerais. (2018b). Portaria no 1.859, de 31 de agosto de 2018. Institui e Regulamenta a Certificação de Queijos Artesanais no Âmbito do Programa Certifica Minas. Instituto Mineiro de Agropecuária. Belo Horizonte, MG.

Moreno, V. (2013). Caracterização física e físico-química do queijo Minas artesanal da microrregião Campo das Vertentes (Doctoral dissertation, Dissertação (Mestrado em Ciências e Tecnologia do Leite e Derivados) Universidade Federal de Juiz de Fora, Juiz de fora, $131 \mathrm{f}$ ).

Nunes, A. C. D., Neto, A. F., Nascimento, I. K., de Oliveira, F. J., \& Mesquita, R. V. C. (2017). Armazenamento de mamão formosa revestido à base de fécula de mandioca. Revista de Ciências Agrárias, 40(1), 254-263.

Oliveira, D. F., Porto, M. A. C., Bravo, C. E. C., \& Tonial, I. B. (2013). Caracterização físico-química de queijos Minas Artesanal produzidos em diferentes microrregiões de Minas Gerais. Oikos: Família e Sociedade em Debate, 24(2), 185-196.

Oliveira, K. G., Queiroz, V. A. V., de Almeida Carlos, L., de Morais Cardoso, L., Pinheiro-Sant'Ana, H. M., Anunciação, P. C., ... \& Barros, F. (2017). Effect of the storage time and temperature on phenolic compounds of sorghum grain and flour. Food Chemistry, 216, 390-398.

Oliveira, L. (2014). Caracterização microbiológica e físico-química durante a maturação em diferentes épocas do ano de queijo Minas artesanal de produtores cadastrados da mesorregião de Campo das Vertentes-MG. 111p (Doctoral dissertation, Dissertação (Mestrado em Ciência Animal), Escola de Veterinária, Universidade Federal de Minas Gerais, Belo Horizonte). 
Oliveira, V. (2010). Da Qualidade e Organização da Produção ao Reconhecimento de Região Produtora de Queijo Minas Artesanal: Análise da Experiência dos Produtores da Região de São João del-Rei e seu Entorno. 204 p (Doctoral dissertation, Tese (Doutorado em Ciência dos Alimentos) - Universidade Federal de Lavras, Lavras).

Pinto, M. S., Ferreira, C. L. D. L. F., Martins, J. M., Teodoro, V. A. M., dos Santos Pires, A. C., Fontes, L. B. A., \& Vargas, P. I. R. (2009). Segurança alimentar do queijo Minas artesanal do Serro, Minas Gerais, em função da adoção de boas práticas de fabricação. Pesquisa Agropecuária Tropical, 39(4), 342-347.

Perin, L. M., Moraes, P. M., Viçosa, G. N., Júnior, A. S., \& Nero, L. A. (2012). Identification of bacteriocinogenic Lactococcus isolates from raw milk and cheese capable of producing nisin A and nisin Z. International Dairy Journal, 25(1), 46-51.

Queiroz, V. A. V., Moraes, É. A., Queiroz, L. R., Tardin, F. D., Guedes, E. D. O., Pereira Filho, I. A., \& Lombardi, C. T. (2010). Utilização de cobertura comestível na conservação pós-colheita de minimilho minimamente processado. Food Science and Technology, 30(4), 910-916.

Raybaudi-Massilia, R. M., Mosqueda-Melgar, J., \& Martín-Belloso, O. (2008). Edible alginatebased coating as carrier of antimicrobials to improve shelf-life and safety of fresh-cut melon. International Journal of Food Microbiology, 121(3), 313-327.

Resende, M. D. F. S. (2010). Queijo minas artesanal da serra da canastra: influência da altitude e do nível de cadastramento das queijarias nas características físico-químicas $e$ microbiológicas. (Doctoral dissertation, Dissertação (Mestrado em Tecnologia e Inspeção de produtos de Origem Animal) - Escola de Veterinária, Universidade de Minas Gerais, Belo Horizonte, MG).

Resende, M. F. S., Costa, H. H. S., Andrade, E. H. P., Acúrcio, L. B., Drummond, A. F., Cunha, A. F., ... \& Souza, M. R. (2011). Queijo de minas artesanal da Serra da Canastra: influência da altitude das queijarias nas populações de bactérias ácido-lácticas. Arquivo Brasileiro de Medicina Veterinária e Zootecnia, 63(6), 1567-1573.

Ross, R. P., Morgan, S., \& Hill, C. (2002). Preservation and fermentation: past, present and future. International Journal of Food Microbiology, 79(1-2), 3-16.

Saint-Hilaire, A. (1974). Viagem pelo Distrito dos Diamantes e litoral do Brasil: o viajante esteve na vila nas primeiras décadas do século XIX. Livraria Itatiaia, Belo Horizonte.

Sant'Anna, F. M., Acurcio, L. B., Alvim, L. B., De Castro, R. D., De Oliveira, L. G., Da Silva, A. M., ... \& Souza, M. R. (2017). Assessment of the probiotic potential of lactic acid bacteria isolated from Minas artisanal cheese produced in the Campo das Vertentes region, Brazil. International Journal of Dairy Technology, 70(4), 592-601.

Santos, A. J. P. D. (2016). Efeitos do período de maturação de queijos sobre a microbiota deteriorante e Listeria monocytogenes. 36 p. (Dissertação apresentada ao Curso de PósGraduação Stricto Sensu em Saúde Animal) - Faculdade de Agronomia e Medicina Veterinária da Universidade de Brasília, Brasília). 
Santos, A. S. (2010). Queijo minas artesanal da microrregião do Serro-MG: efeito da sazonalidade sobre a microbiota do leite cru e comportamento microbiológico durante a maturação. 68 p. (Dissertação apresentada ao Curso de Pós-Graduação Stricto Sensu em Produção Animal) Faculdade de Ciências Agrárias da Universidade Federal dos Vales do Jequitinhonha e Mucuri, Diamantina).

Sapelli, K. S., Faria, C. M. D. R., \& Botelho, R. V. (2020). Conservação pós-colheita de pêssegos com aplicação de revestimentos aditivados de extrato de erva-mate. Brazilian Journal of Food Technology, 23.

Silva, A. M., Penna, C.F. A. M., Sant'anna, F.M., Silva, G.O., Assis, G. S., Silva, J.G., Valente, G.L.C., Acurcio, L. B., Oliveira, L.G., Souza, M.R., Figueiredo, N.C., Figueiredo, R.C., \& Castro, R.D. (2019). Queijo Minas Artesanal. Cadernos Técnicos, 95, 5 - 55.

Silva, N., Junqueira, V. C. A., Silveira, N. F. A., Taniwaki, M. H., Santos, R. F. S., \& Gomes, R. A. R. (2010). Manual de Métodos de Análise Microbiológica de Alimentos e Água: Varela. São Paulo.

Sousa, Y. A., Borges, M. A., Viana, A. F. D. S., Dias, A. L., Sousa, J. J. V. D., Silva, B. A. D., Silva, S. K. R., \& Aguiar, F. S. D. (2020). Avaliação físico-química e microbiológica de polpas de frutas congeladas comercializadas em Santarém-PA. Brazilian Journal of Food Technology, 23.

Stülp, M., Clemente, E., Oliveira, D. M., \& Gnas, B. B. B. (2012). Conservação e qualidade de mirtilo orgânico utilizando revestimento comestível a base de fécula de mandioca. Revista Brasileira de Tecnologia Agroindustrial, 6(1), 713-721.

Tiveron, A. P., Melo, P. S., Bergamaschi, K. B., Vieira, T. M., Regitano-d'Arce, M. A., \& Alencar, S. M. (2012). Antioxidant activity of Brazilian vegetables and its relation with phenolic composition. International Journal of Molecular Sciences, 13(7), 8943-8957.

Team, R. C. (2016). R: A Language and Environment for Statistical Computing.

Zamudio-Flores, P. B., Bautista-Baños, S., Salgado-Delgado, R., \& Bello-Pérez, L. A. (2009). Effect of oxidation level on the dual modification of banana starch: The mechanical and barrier properties of its films. Journal of Applied Polymer Science, 112(2), 822-829. 